\title{
PLANIFICACIÓN PRESUPUESTARIA Y DESARROLLO EN COSTA RICA
}

\author{
ROLANDO BOLAÑOS GARITA \\ Escuela de Ciencias de la Administración \\ Universidad Estatal a Distancia, Costa Rica \\ rbolanos@uned.ac.cr
}

\section{RESUMEN}

El fin primordial del presente aporte fue determinar la vinculación entre el Plan Nacional de Desarrollo y los presupuestos públicos sometidos a aprobación de la Asamblea Legislativa por parte del Poder Ejecutivo, esto tomando en cuenta que entre ambos debería darse un ligamen irrompible, dirigido indefectiblemente hacia el desarrollo nacional, sea en el campo educativo, de salud pública, infraestructura vial, resguardo del ambiente, por citar solo algunos. Lo anterior, con sustento en la Constitución Política, en la Ley de Planificación Nacional 5525 y en la Ley de Administración Financiera de la República y Presupuestos Públicos 8131.

PALABRAS CLAVE: PLANIFICACIÓN PRESUPUESTARIA, PROYECTOS PÚBLICOS, DESARROLLO NACIONAL.

\section{ABSTRACT}

This contribution is a result of a doctoral thesis developed in the System of Postgraduate Studies at UNED. Its primary purpose is to determine the connection between the National Development Plan and the public budgets submitted for approval to the Legislative Assembly by the Executive Branch, considering that there should be a close ligament between the two which should ensure the national development in education, public health, road infrastructure, the environment, among others. This study is based on the Constitution, the National Planning Act 5525, the Financial Administration Act of the Republic and the Public Budgets 8131.
KEYWORDS: BUDGET PLANNING, PUBLIC PROJECT, NACIONAL DEVELOPMENT.

\section{INTRODUCCIÓN}

Este artículo pretende considerar aspectos de gran variedad, para así proveer a diversos órganos y organismos públicos, de datos valiosos y actualizados que bien pueden ser empleados para re-direccionar lo tocante a la dirección y la planificación del desarrollo en todo el territorio nacional, sin distingos del campo de actividad que se requiera: social, educativo, agroalimentario, económico, etc.; y sin que se obvie o excluya a ninguna institución de la Administración Central o Descentralizada.

En sintonía con lo anterior, resulta primordial que el Sistema Nacional de Planificación y el Sistema de Administración Financiera, logren funcionar de manera complementaria y sincronizada, buscando el cumplimiento y sostenimiento de aquellas pautas establecidas en la Constitución Política y en el resto del marco normativo costarricense.

Precisamente, la presente investigación aborda los Sistemas en mención, con la clara visión de que el Poder Ejecutivo debe estar en capacidad de activar ambos y que funcionen como partes bien aceitadas de un engranaje burocrático, buscando cortar la "grasa" presupuestaria y fortalecer 
únicamente el músculo operativo que se destine al desarrollo nacional vía Plan Nacional de Desarrollo (PND), pero cimentado este último por lo plasmado en la Constitución Política y en las leyes que propugnan necesidades poblacionales y derechos de los habitantes, así como en otorgar prioridades a obras públicas indispensables para cumplir lo anterior (carreteras, puertos, acueductos, telecomunicaciones, salud, vivienda, educación, entre otros).

También, se buscó proponer un re-direccionamiento del modelo inherente a la planificación presupuestaria en Costa Rica desde la óptica de las Ciencias de la Administración, a fin de que se reflejen la serie de consideraciones que sí permitan la concreción de presupuestos de la República alineados con las necesidades poblacionales interpretadas y detectadas por medio del Sistema Nacional de Planificación, buscando que el país, correlativamente, logre estándares de desarrollo óptimos, dejando atrás finalmente la clasificación de subdesarrollado y posicionándose entre los primeros lugares a nivel mundial en aspectos como: competitividad, infraestructura e innovación, por citar solo algunos.

Bajo esa tesitura, la investigación realizada podemos visualizarla a través de dos corrientes principales: la justificación práctica a través de la aplicabilidad de las Ciencias de la Administración y la justificación de pertinencia socioadministrativa.

La primera atiende a la inexorable necesidad de analizar y, consiguientemente, llevar a cabo un diagnóstico sobre las implicaciones estratégicas y operativas que redundan en la planificación presupuestaria a nivel de la Administración Pública costarricense. Dichas implicaciones deben comprender, entre otras, las etapas del Proceso Presupuestario: formulación, aprobación, ejecución, control y evaluación, pero, alineadas estas desde todos sus ángulos con el mejor cumplimiento del Plan Nacional de Desarrollo y los consiguientes Planes Sectoriales y Regionales, en tanto ambos devienen en instrumentos formulados en sujeción estricta al primero.

En cuanto a la segunda, la justificación socioadministrativa de la investigación, la ubicamos a partir del uso que los niveles jerárquico-gerenciales, políticos y técnicos pueden darle a la investigación, para así emplear la gama de teorías, conceptos e instrumentos provistos por las Ciencias Administrativas en la toma de decisiones gubernativas, enfatizando la necesidad urgente de lograr una planificación presupuestaria concatenada con los instrumentos de dirección gubernativa con que cuenta el Poder Ejecutivo para abordar la serie de necesidades nacionales insatisfechas.

En otras palabras, los esquemas teórico-conceptuales, y los hallazgos y propuestas administrativos extraídos y generados a la luz de esta investigación, deben servir de insumo para el mejor desempeño de la Administración Pública, para que ésta logre impactar en los estratos sociales a los cuales se debe el Gobierno costarricense, lo cual es posible a través del arsenal teórico y técnico que ostentan las Ciencias de la Administración.

Tampoco resulta viable desde una perspectiva de equilibrio de las finanzas públicas, que el Gobierno asuma compromisos económicos para, nuevamente, destinarlos a una gestión administrativa (presupuestaria y operativa) en las instituciones públicas que echa mucho de menos las necesidades de todos los grupos sociales dependientes del mejor accionar gubernamental. En caso de incurrir en ello, estaríamos no solo frente a un escenario de ineficiencia e ineficacia, sino ante una evidente ilegalidad en el desempeño de los niveles gerenciales y po- 
líticos de la Administración Pública, quebrantando tanto el orden constitucional, como del equilibrio financiero y del resto de normas relativas a las finanzas y el presupuesto público.

\section{El alcance de la investigación}

El estudio comprende la estructura programática-presupuestaria de algunas de las dependencias ministeriales del Poder Ejecutivo a las cuales se les aprobó el Presupuesto Ordinario y Extraordinario mediante Ley de la República, durante los periodos 2007-2010 y 2011-2012, exceptuando al Poder Judicial y al Tribunal Supremo de Elecciones, en razón de la autonomía constitucional de la que gozan ambos órganos. Salvo esas excepciones, el resto de dependencias públicas a las que se les dota de recursos presupuestarios también deberían verse reflejadas en Acciones y Metas específicas en el Plan Nacional de Desarrollo (PND) de los periodos referidos, denominados "Jorge Manuel Dengo Obregón"y "María Teresa Obregón Zamora", respectivamente. A la fecha, las carteras ministeriales suman dieciocho, pero nuestro abordaje investigativo comprende a la mitad de ellas, o sea, 50\% de la población ministerial.

Nótese que dicha población debería, según el marco normativo dispuesto, abonar mediante acciones específicas a los Indicadores Globales de Logro establecidos en el respectivo Plan Nacional de Desarrollo, el cual a su vez debe desagregarse en Planes Sectoriales y Planes Regionales, todos ellos focalizados en el cumplimiento concreto de las Acciones y Metas propuestas para el desarrollo nacional.

La desagregación anotada da pie a una transversalidad en la esquematización del desarrollo nacional vía planificación presupuestaria, ya que el nivel de dependencia pública puede referirse a todo un ente ministerial, o sólo a una de sus instancias desconcentradas ubicada a nivel presupuestario como un "Programa". Por lo tanto, el espacio de acción principal de la investigación comprende al Gobierno Central costarricense en el sentido amplio del término, refiriéndonos con ello a la Presidencia de la República, a los Ministerios y sus instancias adscritas.

\section{EL ENCUADRE INVESTIGATIVO La hipótesis de trabajo}

Existe una disfuncionalidad entre el Sistema de Planificación Nacional y el Sistema de Administración Financiera, la cual no permite concretar una óptima planificación presupuestaria pública y un mejor desarrollo nacional a través del cumplimiento del Plan Nacional de Desarrollo.

\section{El objetivo general}

Analizar las dimensiones que vinculan la planificación presupuestaria con el Plan Nacional de Desarrollo (administrativa, conceptual, política y jurídica), a fin de identificar la disfuncionalidad entre los sistemas administrativos inherentes a esa vinculación. - Investigación-

\section{Algunas consideraciones diagnósticas}

Ahora bien, referirse a las dimensionas que condicionan la vinculación entre la planificación presupuestaria y el PND, conlleva primero a aclarar la inexorable interrelación entre todas ellas, ya que constituyen un andamiaje que sustenta, articula y da coherencia al desarrollo nacional y a la mejor consecución de acciones administrativas para solventar las necesidades poblacionales en los campos que se requieran. Esta interrelación es en nuestro criterio irrompible, considerando que una condiciona a las otras (ver figura 1). 


\section{INTERRELACIÓN ENTRE DIMENSIONES}

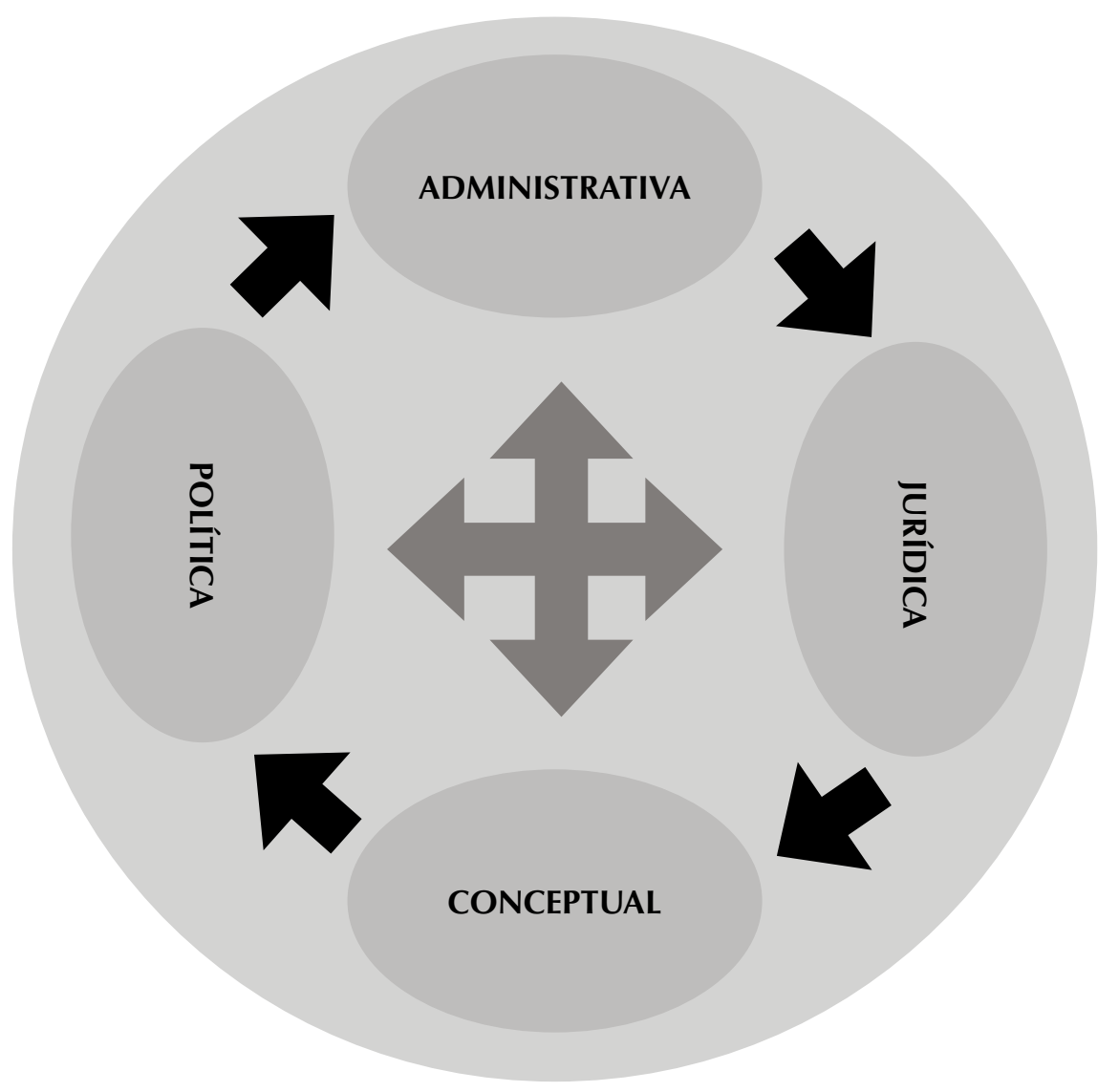

Fuente: Elaboración propia

\section{Dimensión Política}

Siguiendo la tesis de Meoño Segura (2011), la dimensión política la concebimos a partir de que el Presidente de la República accede al cargo por el periodo constitucional respectivo, e inicia el proceso de modelización del desarrollo nacional, trasplantando el Programa de Gobierno del partido político por medio del cual gana las elecciones, hacia el Plan Nacional de Desarrollo.

Entonces, esa dimensión dimana, según nuestro discernimiento, de la misma Constitución Política, la cual asigna deberes y atribuciones al Poder
Ejecutivo, sobre todo para la mejor conducción de todo el Sistema de Administración Pública hacia el desarrollo nacional; precisamente, serían los artículos 50 y 140 incisos 3, 8 y 18, los cuales activan esa potestad.

Posteriormente, debemos referirnos a la Ley de Planificación Nacional 5525, a la Ley de Administración Financiera de la República y Presupuestos Públicos (LAFRPP) 8131, la Ley de Equilibrio Financiero para el Sector Público 6955, la Ley General de Administración Pública (LGAP) 6227 y, si se quiere, la Ley de Contratación Administrativa 7494 (LCA). 
La ley 5525 da fundamento al Sistema Nacional de Planificación y al MIDEPLAN, el cual previo a la reforma generada a esa norma en el año 1984, contenía al departamento encargado de preparar los proyectos de presupuesto bajo la forma de presupuesto por programas, por lo cual se preveía y se legalizaba en cierta forma el ligamen Plan-Presupuesto, o sea, se buscaba materializar una efectiva planificación presupuestaria.

Precisamente, es la Ley 5525 la que genera la capacidad de dirección y planificación a nivel regional en Costa Rica, buscando canalizar los recursos humanos, técnicos y financieros de orden público, hacia las necesidades poblacionales de cada región del país, en tanto que cada una, conforme sus elementos contextuales, tendrá aquellas que la particularicen: infraestructura vial, desarrollo agroalimentario, salud, etc. Lo anterior permite entrever que es por medio de la norma de cita que se da sustento al término "regionalización", como mecanismo para abordar segregativamente las carencias comunales que terminarán generando acciones estratégicas por medio del modelo planificador diseñado a la luz de esta investigación.

Por su parte, la Ley 6227 da pie a dos factores determinantes en materia de planificación presupuestaria: 1) la segregación de acciones administrativas a fin de encauzar los objetivos, deberes y responsabilidades de cada institución pública de acuerdo con su Actividad', o sea, lograr la Sectorialización administrativa; 2) ordenar el accionar de todo el Sistema de Administración Pública y encauzarlo hacia el desarrollo nacional a través de las fases de dirección y planificación global/nacional, regional y sectorial, todo esto a

1. El término "Actividad", específicamente en lo tocante a un ente público, ha sido desarrollado profusamente por el autor Johnny Meoño Segura, por lo que referimos al lector a la obra de éste titulada Guía para un excelente Gobierno y... para un ciudadano menos indolente, en su Capítulo 3. través de la generación de instrumentos de dirección gubernativa denominados directrices.

Es a través de los artículos 26 b) y c), 27.1, 98.1, 99.1 y 100.1 y 2 de la LGAP, como se legitima esa capacidad del Poder Ejecutivo de dirigir a las instituciones públicas, sean de la Administración Central y Descentralizada, principalmente, y como se indicó antes, a través de la emisión de directrices según el artículo 99 indicado, e imponiendo las Metas y Tipos de Medios que, con base en la planificación nacional, mejor resulten para el cumplimiento de la misma.

En lo relativo a la LAFRPP, es esta la que finalmente termina de aclarar la actuación de las instituciones públicas en razón del desarrollo nacional dictado por el Presidente de la República por medio del PND vía presupuestos públicos, y el papel que juegan los jerarcas de MIDEPLAN y del Ministerio de Hacienda como responsables de lograr la articulación de lo hasta aquí señalado, en fiel apego a las responsabilidades asignadas a los sistemas administrativos de los cuales son responsables: Sistema de Planificación Nacional y el Sistema de Administración Financiera, respectivamente.

Todo lo anterior obliga a abordar conexivamente las tres normas anteriores para comprender manera de lograr la activación, el funcionamiento sinérgico y el cumplimiento del modelo planificador que se presenta como parte de las propuestas de esta investigación, el cual aglutina las capacidades del Poder Ejecutivo ya plasmadas en la normativa vigente.

Entonces, la dimensión política que logra esa vinculación entre la planificación presupuestaria y el PND vigente, se resume en esa responsabilidad y atribución del Poder Ejecutivo de lograr la dirección política del Sistema de Administración Pública en todo su conglomerado (Sistemas de Planificación Nacional y de Administración Financiera incluidos), enrumbando a éste hacia el desarrollo nacional por medio de los mecanis- 
mos y elementos que son partes coyunturales de las dimensiones administrativa, jurídica y conceptual, y que se especificarán en lo siguiente.

\section{Dimensión Jurídica}

Esta dimensión la concebimos como la forma en que se ha dado rango legal a aquellas iniciativas de corte y aplicación administrativa, y nos explicamos mejor. Se debe considerar el principio de legalidad conceptuado por Miguel Ángel Rodríguez (1993), el cual señala que las instancias administrativas públicas, concebidas por él como el Estado en términos amplios, sólo pueden realizar aquellos cometidos que se les han encomendado, y sólo pueden efectuarlos a través de los órganos especiales a los cuales se les haya conferido su realización; esto puede lograrse por medio de la emisión de leyes y de aquellas otras normas de menor rango desprendidas de las primeras.

Esto es así porque nuestra Constitución Política en su artículo 11 lo establece, y el artículo 11 de la LGAP lo enfatiza y amplía. Es parte del también Ilamado Estado de Derecho, conceptuado por Pacheco (2007).

Desde esa premisa, la dimensión jurídica que obliga y logra esa vinculación entre la planificación presupuestaria y el PND, se cristaliza por medio de la emisión de normas, principalmente: Decretos, Acuerdos y Directrices, que pasan a formar parte del arsenal jurídico que permite la dirección política del Poder Ejecutivo hacia la totalidad del Sistema de Administración Pública.

Cuando esto no se comprende, o sea cuando no se abordan conexivamente las leyes vigentes que dan sustento y fuerza a la vinculación de referencia; primero a través de la sincronía e interrelación sinérgica que debe existir entre los Sistemas de Planificación Nacional y de Administración Financiera. Posteriormente, por medio del empleo que los jerarcas de éstos junto con el Presidente de la República dan a los instrumen- tos normativos que encauzan el desempeño de las instituciones públicas por medio de la planificación presupuestaria. Ocurre, finalmente, una suerte de tinglado de tipo: jurídico, presupuestario y sobre todo administrativo.

El tinglado jurídico lo consideramos en razón de que la emisión de instrumentos normativos poco direccionados para lograr la vinculación entre la planificación presupuestaria y el PND es incurrir en el error jurídico, disponiendo la emisión de toda una gama de normas que al fin y al cabo poco o nada agregan para materializar dicha vinculación; entonces, únicamente se inunda al Sistema de Administración Pública de disposiciones ineficaces que con el tiempo perduran, pero que no tienen impacto positivo para el desarrollo nacional.

Valga reiterar que la Sala Constitucional del Poder Judicial ya aclarado en ocasiones anteriores, por ejemplo en su Resolución 2002-12019, que las instituciones de la Administración Central y Descentralizada están sujetas a la dirección gubernativa del Poder Ejecutivo, principalmente por medio de la emisión de directrices en razón de la planificación nacional del desarrollo. Propiamente la resolución de referencia aclara lo relativo a las directrices que vinculen la inversión pública, el endeudamiento y los superávits financieros a la propia planificación nacional del desarrollo, en total apego, respeto y armonía con el artículo 50 constitucional.

Entonces, únicamente resta que el ápice jerárquico gubernativo termine de comprender el provecho y efectividad que significa hacer uso de los instrumentos normativos de marras, con el firme propósito de eliminar la disfuncionalidad entre los sistemas administrativos costarricenses que tienen incidencia directa en la vinculación planificación presupuestaria - PND.

El tinglado presupuestario lo notamos al analizar la formulación presupuestaria mediante el Proyecto de Presupuesto de la República: una 
estructura programática con Objetivos de todo tipo que poco o ningún engarce tienen con el PND o con las Actividades de las instituciones públicas; recursos presupuestarios sin justificación o engarce también con el PND; igualmente, recursos aparentemente con ligamen en el PND pero de naturaleza intermitente; y peor aún, recursos que apoyan acciones sin término y con un bajísimo nivel de ejecución presupuestaria.

Finalmente, el tinglado administrativo se concreta cuando las instituciones, tanto de la Administración Central como de la Descentralizada, incurren en la desatención de sus responsabilidades establecidas por ley, porque no fueron tomadas en cuenta al no considerar adecuadamente su Actividad, y por ende no pasan a formar parte del esquema de la planificación presupuestaria, o porque cuando se asignan acciones estratégicas en el PND que son responsabilidad de un ente ministerial en particular, incoherentemente se les asignan a otras instancias, tal y como ocurrió en el caso del Ministerio de Salud y su dedicación a los CEN-CINAl: para el presupuesto 2012 la construcción, ampliación y reparación de estos centros por un monto de \$400 millones le fue asignada presupuestariamente al Ministerio de Obras Públicas y Transportes (MOPT).

En casos como los indicados en el párrafo anterior se logran evidenciar dos desproporciones o extremos carentes de sentido: 1) la duplicidad o superposición de funciones, o 2) la ausencia total de participación por parte de las instituciones públicas cuando sí les corresponde.

\section{Dimensión Administrativa}

Muy ligada con la anterior, tal y como pudo denotarse en los últimos párrafos anotados, la dimensión administrativa debe dimensionarse en razón del accionar conjunto, el cual debe lograr todo el Sistema de Administración Pública, en razón del esquema de planificación presupuestaria auténticamente costarricense.
Lograr el desempeño articulado, orquestado, interrelacionado y armónico de los Sistemas de Planificación Nacional y de Administración Financiera mediante el respeto absoluto a lo establecido en las Leyes 5525 y 8131, es posible precisamente a través de las potencialidades y posibilidades que brinda a su vez la Ley 6227, justamente a través del ordenamiento de la Actividad de todas las instituciones a partir de una adecuada Sectorialización gubernativa, lo cual permite aclarar en qué debe desempeñarse cada una en función del PND y más adelante a nivel de Planes Sectoriales; en forma yuxtapuesta está la Regionalización, la cual obliga y permite atender las necesidades poblacionales con la especificidad que el contexto territorial brinda a cada región.

Y en descenso encontramos los presupuestos públicos, los cuales, según lo indicado, estarían en armonía con los niveles superiores de planificación presupuestaria de primer, segundo, tercer y cuarto grado, en tanto que estarían plenamente dispuestos para el logro de los Proyectos de orden nacional que solventarán las necesidades poblacionales en los campos de acción que se requieran: educación, salud, infraestructura vial, resguardo del ambiente, etc.

Precisamente, la disfuncionalidad entre los Sistemas de Planificación Nacional y de Administración Financiera, con motivo del poco o nulo entendimiento de las atribuciones y responsabilidades que los encargados de estos deben lograr con sustento y apego en primer lugar a la Constitución Política, y posteriormente de las Leyes 5525 y 8131 respectivamente, se traducirá tarde o temprano por un efecto multiplicador en descenso en una disfuncionalidad de todo el Sistema de Administración Pública, tanto en acciones administrativas de naturaleza inconexa, como en la gestión presupuestaria errática en general. 
Y es que la gestión presupuestaria no está en ningún momento desligada del Proceso Administrativo (Dirección, Planificación, Organización, Coordinación, Control y Evaluación), encontrando más bien que dentro de éste se localiza el Proceso Presupuestario en sus fases de Formulación, Aprobación, Ejecución, Control y Evaluación. Por lo tanto, el desarrollo inadecuado de cualquiera de estas fases lleva implícitamente al quebranto y desequilibrio del Proceso Administrativo en su totalidad, y no logran en consecuencia que la Administración Pública, en todo su conglomerado, se dirija, planifique, organice, controle y evalúe para lograr el desarrollo nacional por medio del ligamen Plan-Presupuesto.

Por ahora, baste señalar que también la ausencia de proyectos particulares derivados del modelo planificador propuesto, resulta en un disparador más para la disfuncionalidad y la dispersión administrativa costarricense, lo cual impide el desempeño en pro del cumplimiento de las necesidades de los ciudadanos y los habitantes del país.

\section{Dimensión Conceptual}

Llegados a este punto, valga especificar que la dimensión conceptual constituye toda esa red de conceptos de naturaleza exclusivamente administrativa, algunos de los cuales al haber sido pasados por el tamizaje jurídico, o sea, que han sido incorporados a un instrumento de corte normativo (Leyes o Decretos), ahora forman parte del bloque de legalidad costarricense, lo que obliga a cumplirlos y ejecutarlos.

No debe confundirse el hecho de que los términos que han sido normalizados ostentan un mayor valor o respeto que aquellos que aún se circunscriben a la teoría de corte netamente administrativa, ya que: 1) cualquier término puede incorporarse al bloque de legalidad si así lo deciden los órganos político-administrativos costa- rricenses (la Asamblea Legislativa a través de la emisión de leyes, y el Poder Ejecutivo a través de los Decretos Ejecutivos, algunos en calidad de Reglamentos), 2) ambos, los conceptos aún visibles sólo en la teoría administrativa y aquellos pasados por el tamizaje legalizador, están dirigidos a encauzar el accionar del Sistema de Administración Pública, y para nuestro caso particular, hacia aquello que Wilburg Jiménez Castro (1975) define como Administración Pública para el Desarrollo Integral.

Nótese el ligamen entre la dimensión sujeta de comentario y las dimensiones política, jurídica y administrativa, conformándose así todo un mecanismo dinamizador del accionar público hacia una determinada dirección; esa dirección sería el desarrollo nacional vía planificación presupuestaria.

Por lo tanto, esta dimensión es la que contiene todo el arsenal terminológico que debe primeramente comprenderse y posteriormente ejercitarse por parte del Poder Ejecutivo para poder activar el mecanismo dinamizador del desarroIlo, refiriéndonos con esto a todo el Sistema de Administración Pública.

Dicho arsenal incorpora, entre otros, los citados en el Marco Teórico-Conceptual de la investigación y que han sido de recurrente uso para lograr el mejor entendimiento del fenómeno analizado, por ejemplo: Actividad, Dirección gubernativa, Regionalización, Sectorialización, Directriz, Metas y Tipos de Medios, gasto público, Presupuesto, Fases del Proceso presupuestario, Programas presupuestarios, etc.

Tanto el Poder Ejecutivo (Presidente de la República y Ministro del Ramo) como el Poder Legislativo en todo su espectro (Comisión Permanente Ordinaria de Asuntos Hacendarios, Comisión Permanente Especial de Ingreso y Gasto Público y la Contraloría General de la República), deben tener total claridad sobre el alcance y el impacto 
que el arsenal conceptual ostenta para consolidar adecuadas estrategias de desarrollo nacional de orden superior, o sea, que dimana de la Constitución Política y transcurre por el resto de los niveles jurídico-jerárquicos (Leyes, Decretos, Directrices, Circulares, etc.).

A pesar de que la Contraloría General de la República ha aceptado la importancia de algunos de los términos aquí indicados para lograr el encauzamiento administrativo para el desarrollo nacional, e igualmente varia de la terminología se ha incorporado al argot jurídico-administrativo por medio de Decretos Ejecutivos, según lo extraído a partir de esta investigación, el reconocimiento, y sobre todo el uso que los diferentes actores gubernativos hacen de la dimensión conceptual para el desarrollo, ha sido sumamente laxo e inconexo.

En esa misma línea, el Poder Ejecutivo debe tener claridad que puede ordenar la conformación de todo el aparato estatal bajo su alero mediante la Sectorialización administrativa, de forma tal que puede y debe activar mecanismos de convergencia para no solo mapear la gama de necesidades poblacionales en cada kilómetro cuadrado de este país por medio de la Regionalización, sino también desplegar, controlar y evaluar las acciones estratégicas nacidas a raíz de ese mapeo; que puede dirigir el accionar conjunto, articulado y coherente de todas las instituciones públicas mediante el ejercicio de la Rectoría política, y que esto último se logra emitiendo Directrices que terminan siendo según la teoría de Meoño Segura (2008), Políticas Públicas.

Todo esto debe, como lo indicamos al inicio de este acápite, yuxtaponerse para encontrar la ligazón entre las diferentes dimensiones que potencian o reducen la disfuncionalidad entre los Sistemas de Planificación Nacional y de Adminis- tración Financiera, encauzando así a todo el aparato público hacia el desarrollo nacional integral.

Según las consideraciones hasta aquí planteadas, la recomendación emanada del objetivo presentando se dirige al Poder Ejecutivo en las figuras de Presidente de la República y los Ministros de Planificación Nacional y Política Económica, y de Hacienda, de la siguiente manera:

- Reconocer, consolidar y potenciar las dimensiones política, jurídica, administrativa y conceptual que permiten la vinculación armónica de la planificación presupuestaria para con el respectivo Plan Nacional de Desarrollo, haciendo uso de los instrumentos administrativos, jurídicos, técnicos y conceptuales que emanan de todas las anteriores; esto, en cualquiera de las fases del Proceso Presupuestario del Sector Público, instituido mediante el Decreto Ejecutivo 33446- $\mathrm{H}$.

Esto es posible a partir del reconocimiento de un Modelo integral de planificación presupuestaria, el cual conjunte y enlace las dimensiones señaladas, de forma sistémica.

La recomendación se emana en los mismos términos a todo el Poder Legislativo, a fin de que este tenga claridad sobre la forma en que debe exigir al Poder Ejecutivo un mejor desarrollo nacional a través del ligamen Plan-Presupuesto, fiscalizando concomitantemente los esfuerzos alcanzados por este último para activar y ejercitar las potencialidades que le brindan todas las anteriores dimensiones.

A manera ilustrativa, se presenta la figura 2, el cual es un resumen del modelo de planificación presupuestaria criollo, mismo que implícitamente contiene las dimensiones política, jurídica, administrativa y conceptual para el desarrollo integral. 
FIGURA 2

RESUMEN DEL MODELO DE PLANIFICACIÓN

PRESUPUESTARIA EN COSTA RICA

SISTEMA NACIONAL DE PLANIFICACIÓN

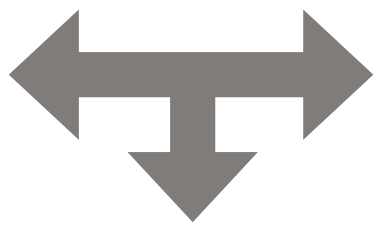

SISTEMA DE ADMINISTRACIÓN FINANCIERA

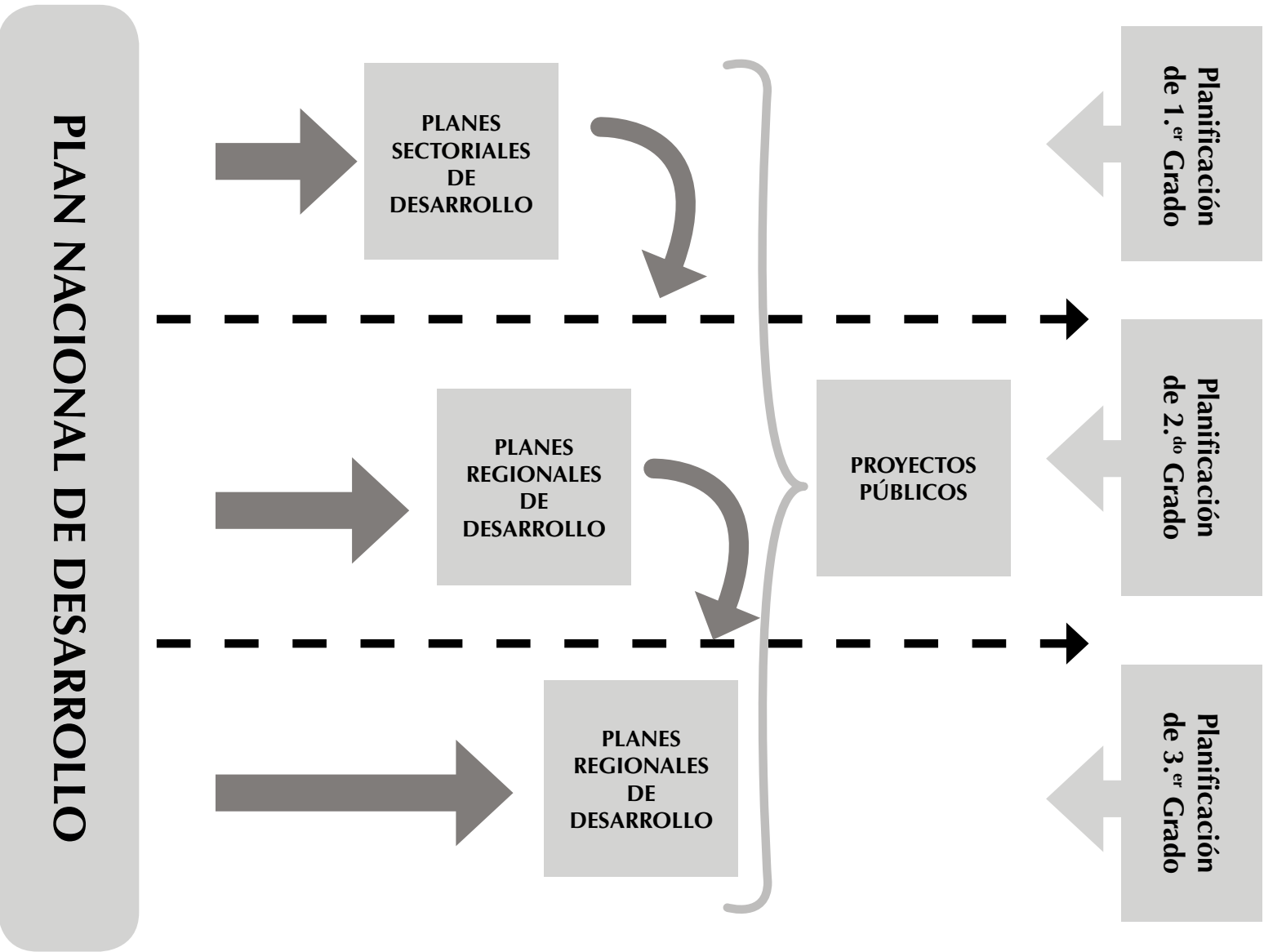




\section{CONCLUSIONES}

Podrá notar el lector interesado, que la capacidad gubernativa para lograr un desarrollo nacional sistémico, sostenible y coherente para con las necesidades poblacionales en todo el territorio nacional, no es una fórmula imposible de descubrir, o bien, exclusiva de otros países. Por el contrario, el esquema planificador y direccionador del desarrollo nacional ya se afinca en el marco normativo vigente, donde brillan con luz propia la Ley de Planificación Nacional 5525, la Ley de Administración Financiera de la República y Presupuestos Públicos 8131 y la Ley General de Administración Pública 6227.

Y es que, las dimensiones política, jurídica, administrativa y conceptual que perfilan y condicionan la planificación presupuestaria costarricense, o sea, el alineamiento al PND y a sus desagregaciones de segundo, tercer y cuarto grado, se constituyen en toda una panoplia que debe ser de conocimiento total por parte de las instancias del Poder Ejecutivo, empezando con el Presidente de la República (máximo administrador y gobernante nacional) y los Ministros de Planificación Nacional y Política Económica, y de Hacienda, hasta llegar a los encargados de Programas Presupuestarios. De igual manera, debe ser comprendida por el Poder Legislativo en todo su espectro (Plenario Legislativo, Comisión Permanente de Asuntos Hacendarios, Comisión de Control de Ingreso y Gasto Público, así como la Contraloría General de la República), con el objetivo de ejercer un adecuado control políticoadministrativo sobre el uso del que están siendo sujetos los limitados recursos públicos.

Cada una de las dimensiones arriba apuntadas se yuxtaponen una a la otra constantemente, en una suerte de interacción que potencia la capacidad del Poder Ejecutivo por lograr dirigir a todo el aparato estatal, y vertebrar así el mejor desarrollo nacional. La ausencia de alguna de ellas termina por materializar el desarraigo de las instituciones públicas para con sus responsabilidades ineludibles en materia de desarrollo nacional, y nos lleva al mismo callejón sin salida del subdesarrollo.

\section{REFERENCIAS}

Asamblea Legislativa de la República de Costa Rica (16 de octubre de 2001). Ley de Administración Financiera de la República y Presupuestos Públicos 8131. La Gaceta 198.

Asamblea Legislativa de la República de Costa Rica (1995). Ley de contratación administrativa 7494. Recuperado de http://www.pgrweb.go.cr/scij/Busqueda/Normativa/Normas/nrm_texto_completo.aspx?param 1=NR TC\&nValor1 $=1 \&$ nValor2=24284\&nValor3=97014\&strTi $\mathrm{pM}=\mathrm{TC}$

Asamblea Legislativa de la República de Costa Rica (30 de mayo de 1978). Ley general de la Administración Pública 6227. La Gaceta N.o 102. Recuperado de http:// www.pgrweb.go.cr/scij/Busqueda/Normativa/Normas/nrm_texto_completo.aspx?param 1=NRTC\&nVa lor1=1\&nValor2=13231\&nValor3=90116\&strTipM=TC

Asamblea Legislativa de la República de Costa Rica. (1984) Ley para el equilibrio financiero del sector público 6955. Recuperado de http://www.pgr.go.cr/scij/busqueda/ normativa/normas/nrm_repartidor.asp?param 1 =NR M\&param2=1\&nValor1=1\&nValor2=6199\&nValor3=8 0883\&strTipM=FN\&|Resultado=1\&strSelect=sel

Asamblea Legislativa de la República de Costa Rica (2008). Ley de Planificación Nacional 5525. Recuperado de http://www.pgr.go.cr/scij/busqueda/normativa/normas/nrm_repartidor.asp?param 1=NRM\&nValor1=1\& nValor2=34439\&nValor3=81449\&strTipM=FN

Bolaños, R. (2014). Planificación presupuestaria en el Administración pública costarricense: su implicancia en el desarrollo nacional. Tesis de Doctorado en Ciencias de la Administración. UNED, Costa Rica.

Jiménez, W. (1975). Administración Pública para el desarrollo integral. -2 edición.-México: Fondo de Cultura Económica.

Meoño, J. (2011). Planificación del Desarrollo. Lecciones de la experiencia. San José: IICE-UCR.

Meoño, J. (2008). Guía para un excelente Gobierno... y para un ciudadano menos indolente. San José: IICE-UCR. 
RNA Revista Nacional de Administración

Ministerio de Gobernación y Policía. (1997). Constitución Política de la República Costa Rica. San José: Imprenta Nacional.

Pacheco, F. A. (2007). Introducción a la Teoría del Estado. -8. reimp. de la 2.ed.—San José: EUNED.

Sala Constitucional del Poder Judicial. Resolución 2002-12019. Recuperado de http://www.pgr.go.cr/scij/busqueda/ normativa/asunto_cons/asu_repartidor.asp?param 1= ASV\&nValor1=1\&strTipM=VT2\&param7=232477\&par am5=96-002914-0007-CO\&param6=1\&nCont=2

Rodríguez, M.A. (1993). Una revolución moral: democracia, mercado y bien común. -1 edición.- San José: Editorial Costa Rica.

Recibido: 24 de febrero de 2014

Aceptado: 10 de abril de 2014 